Л. А. Ленартович, Н. Р. Прокопчук, О. М. Касперович

Белорусский государственный технологический университет

\title{
ЭФФЕКТЫ АНТАГОНИЗМА ПРИ СОВМЕСТНОМ ИСПОЛЬЗОВАНИИ МОДИФИЦИРУЮЩИХ ДОБАВОК В КОМПОЗИЦИЯХ ПЭНД
}

Исследовано совместное влияние различных функциональных добавок на деформационнопрочностные свойства полиэтилена низкого давления (ПЭНД) и их изменение в процессе теплового старения. В работе использованы следующие функциональные добавки: суперконцентрат мелонаполненный EFPP 1001 E-Filler, суперконцентрат гранулированный тальконаполненный ADDITIVE 13169, скользящие добавки ADDITIVE DL 5644 и 5540, антиблокирующие добавки AB 50035 и PE-AB 50035, концентраты пигментов White 41110 и Реалпакс 10030, антистатики AE 50025 и ПО АЭ 23, осушитель POLI-CH DC 451, антипирен FR 400. Определение деформационно-прочностных свойств композиций до и после старения в течение 300 ч при температуре $100^{\circ} \mathrm{C}$ в воздушной среде производили согласно ГОСТ 11262-2017. Выявлен эффект антагонизма при совместном использовании в ПЭНД стабилизирующей добавки Hostanox 03 и пигмента White 41110. Так, после старения в течение 300 ч относительное удлинение для композиции ПЭНД + White 41110 составило 102\%, в то время как при введении в композицию дополнительно стабилизатора Hostanox 03 значения удлинения падают до 79\%, что свидетельствует о возможном взаимодействии добавок, приводящем к снижению эффективности стабилизатора. Аналогичный эффект наблюдается при использовании таких добавок, как скользящая добавка ADDITIVE 5540, осушитель, пигмент Реалпакс 10030, антиблок РЕ-АВ 50035 и антистатик ПОАЭ 23.

Ключевые слова: ПЭНД, стабилизатор, термостабильность, относительное удлинение при разрыве, прочность при растяжении.

Для цитирования: Ленартович Л. А., Прокопчук Н. Р., Касперович О. М. Эффекты антагонизма при совместном использовании модифицирующих добавок в композициях ПЭНД // Труды БГТУ. Сер. 2, Химические технологии, биотехнологии, геоэкология. 2021. № 2 (247). С. 107-114.

\section{A. Lenartovich, N. R. Prokopchuk, O. M. Kasperovich \\ Belarusian State Technological University}

\section{ANTAGONISM EFFECTS WHICH OCCUR IN HDPE COMPOSITIONS MODIFYING ADDITIVES}

The joint effect of various functional additives on the deformation-strength properties of lowpressure polyethylene (HDPE) and their change during heat aging has been investigated. The following functional additives were used in the work: chalk-filled masterbatch EFPP 1001 E-Filler, granular talcfilled masterbatch ADDITIVE 13169, sliding additives ADDITIVE DL 5644 and 5540, antiblocking additives AB 50035 and PE-AB 50035, pigment concentrates White 41110 and Realpax 10030E 50025, antistatics and PO AE 23, dryer POLI-CH DC 451, fire retardant FR 400. Deformation and strength properties of the compositions were determined according to GOST 11262-2017 before and after aging for $300 \mathrm{~h}$ at $100^{\circ} \mathrm{C}$ in air. The antagonism effect was revealed when the stabilizing additive Hostanox 03 and the pigment White 41110 were used together in HDPE. Thus, after aging for $300 \mathrm{~h}$, the elongation for the HDPE + White 41110 composition was $102 \%$, while with the addition of the stabilizer Hostanox 03 to the composition, the elongation values fall to $79 \%$, which indicates a possible interaction of the additives, leading to a decrease in the effectiveness of the stabilizer. Also, a similar effect is observed when using additives such as slip additive ADDITIVE 5540, desiccant, Realpax 10030 pigment, antiblock PE-AB 50035 and antistatic PO AE 23.

Key words: HDPE, stabilizer, heat resistance, elongation at break, tensile strength at strain.

For citation: Lenartovich L. A., Prokopchuk N. R., Kasperovich O. M. Antagonism effects which occur in HDPE compositions modifying additives. Proceedings of BSTU, issue 2, Chemical Engineering, Biotechnologies, Geoecology, 2021, no. 2 (247), pp. 107-114 (In Russian).

Введение. Применение полимерных материалов в различных областях жизни человека требует от них устойчивости к воздействию повышенных температур в присутствии кислорода воздуха, УФ-излучения, повышенных де- формационно-прочностных, диэлектрических, фрикционных свойств, жесткости, морозостойкости, отличного внешнего вида. Для этих целей разработан целый ряд функциональных добавок, таких как стабилизаторы, наполнители, 
поглотители кислот, смазывающие, антиблокирующие, скользящие, процессинговые и другие добавки. Совместное использование в композициях таких добавок может приводить как к синергическим, так и антагонистическим эффектам или без видимых эффектов взаимодействия. Данный факт должен быть учтен при составлении рецептур полимерных композиций с целью получения материалов с наилучшим комплексом свойств без возможного перерасхода дорогостоящих добавок. Важнейшим направлением исследований является изучение влияния компонентов полимерных композиционных материалов (ПКМ) на устойчивость к различным видам деструкции как при их использовании в отдельности, так и при совместном введении. Влияние основных компонентов ПКМ и их комбинаций на устойчивость композиций к воздействию температуры в присутствии кислорода воздуха рассмотрено в работах [1-14]. Приведем некоторые из них.

При исследовании композиций, содержащих в качестве антипиренов модифицированные вискозные волокна (ВВ) - органические соединения, являющиеся производными диметилметилфосфоната различных марок, происходит увеличение кислородного индекса с 19\% (исходное ВВ) до 26,5-28\% (модифицированное волокно). Методом инфракрасной спектроскопии доказано химическое взаимодействие антипиренов с волокном. Анализ деформационно-прочностных свойств показал, что введение в ВВ различных антипиренов не изменяет разрывную нагрузку и незначительно снижает относительное удлинение при разрыве [1].

Антагонизм наблюдается при совместном использовании аминных светостабилизаторов HALS и процессинговых добавок на основе фторполимеров. Указанные добавки содержат в качестве сомономера хлоруглеводородные фрагменты, отщепляющие $\mathrm{HCl}$ при переработке, следствием чего является также снижение светостабильности полимерного материала. Кроме того, HALS конкурируют с процессинговыми добавками, адсорбируясь во время экструзии на металлических поверхностях (фильерах) и снижая эффективность их действия. Аналогичный эффект наблюдается при совместном использовании HALS с галогенсодержащими антипиренами. Вредоностное влияние бромсодержащих антипиренов на УФ-стабильность полимера обусловлено инактивацией стабилизатора бромистоводородной кислотой за счет образования пиперидиновой соли [2].

Экспериментальные данные для композиций, содержащих смесь светостабилизаторов LS-1 и LS-2 в соотношении 1:1, указывают, что использование талька приводит к снижению устойчивости к фотоокислению. Полученные данные свидетельствуют о необходимости комплексного подхода к стабилизации наполненных систем, учитывающего возможность взаимодействия стабилизатора и наполнителя, а также корректировку дозировки стабилизирующих добавок [3].

Авторами [4] изучено взаимодействие между коммерческими стерически затрудненными пиперидиновыми соединениями, первичными и вторичными антиоксидантами и техническим углеродом двух типов при термоокислении полиэтилена низкой плотности (ПЭНП). Незначительные эффекты антагонизма и синергизма установлены между HALS и техническим углеродом в зависимости от химического строения HALS. Bce обнаруженные антагонистические эффекты были ликвидированы за счет синергического взаимодействия, возникающего при введении комбинаций трех и четырех стабилизирующих добавок.

В работе [5] показано, что частичная замена антипирена полифосфата аммония на углеродные нанотрубки приводит к возникновению явлений антагонизма между этими двумя соединениями. В противоложность, введение антипирена с полиэдрическим олигомерным октаметилсилсесквиоксаном приводит к значительному синергическому эффекту.

Наилучший стабилизирующий эффект повышения термостабильности ПА6, содержащего стекловолокно, достигается при введении смесевых медьсодержащих добавок (Polead 201, Polead 101). Этот эффект прослеживается как в отношении стабилизации свойств, так и цвета (в особенности это относится к добавке Polead 101). Данная добавка содержит в своем составе органический фосфит, который не только является вторичным антиоксидантом, разрушающим гидроперекиси, но и способен образовывать устойчивые комплексы с металлами переменной валентности $(\mathrm{Fe})$, которые содержатся в виде примесей, попадающих в ПА-6 из сырья, и способствуют ускорению процессов деструкции. Также можно предположить образование комплекса между $\mathrm{Cu}$ и $\mathrm{P}$ содержащим соединением, который является более эффективным антиоксидантом [6].

Перспективным направлением при защите термопластичных материалов от действия УФ-облучения может быть введение в эти материалы комбинированных добавок (оксид-сульфид металла). При этом добавка в полимер смеси $2 \%$ $\mathrm{ZnO}$ и $2 \% \mathrm{ZnS}$ приводит при УФ-облучении композиции к синергическому эффекту в отношении стабильности деформационно-прочностных свойств [7]. 
При совместном использовании фосфорсодержащих соагентов типа гипофосфитов и медьсодержащих стабилизаторов в ПА происходит восстановление меди. Процесс образования коллоидной взвеси меди сопровождается изменением окраски и потерей эффективности стабилизации [8].

При использовании соли жирных кислот стеарата цинка (смазка) в стеклонаполненных композициях необходимо учитывать ее возможное конкурирующее взаимодействие с аминосилановым аппретом стекловолокна за счет образования координационной связи цинк азот, приводящее к снижению механических показателей [9].

С помощью метода термогравиметрического анализа исследованы композиции полиэтилена высокой плотности (ПЭВП), содержащие гидрофильный / гидрофобный диоксид кремния и антиоксидант бутилгидрокситолуол (БГТ). Обнаружено, что введение наполнителя и стабилизатора в полимер повышает устойчивость к термоокислительной деструкции. Связанный БГТ является неактивным и на начальном этапе подавляет стабилизирующий эффект гидрофобной поверхности диоксида кремния в процессе термоокисления. При постепенной миграции антиоксиданта с поверхности увеличивается устойчивость полимера к окислению [10].

В работе [13] изучено влияние диоксида титана на свойства ПЭВД. Присутствие диоксида титана повышает стабильность ПЭВД к воздействию УФ-излучения, а также тепловому воздействию или воздействию влаги.

Основная часть. Целью данной работы было изучение совместного влияния различных функциональных добавок на свойства композиций на основе ПЭНД, изменяющиеся под влиянием повышенной температуры и кислорода воздуха. В ходе исследований определены изменение деформационно-прочностных свойств композиций, плотность и твердость по Шору Д, а также рассчитаны значения энергии активации термоокислительной деструкции. Для защиты композиций от термооксилительной деструкции применяли фенольный антиоксидант Hostanox O3 фирмы Clariant. В работе были использованы следующие функциональные добавки: суперконцентрат мелонаполненный ЕFРР 1001 E-Filler, суперконцентрат гранулированный тальконаполненный ADDITIVE 13169, скользящие добавки ADDITIVE DL 5644 и 5540, антиблокирующие добавки АВ 50035 и $\mathrm{PE}-\mathrm{AB} 50035$, концентраты пигментов White 41110 и «Реалпакс 10030», антистатики AЕ 50025 и ПО АЭ 23, осушитель POLI-CH DC 451, антипирен FR 400. Образцы для испытаний получали ме- тодом литья под давлением на термопластавтомате BOY 22A (Dr. Boy, Германия).

Деформационно-прочностные характеристики образцов типа 2 до и после термического старения в среде воздуха при температуре $(100 \pm 2)^{\circ} \mathrm{C}$ в течение 300 ч определяли на разрывной машине «Тензометр T2020 DC10 SH» (Alpha Technologies UK, США) согласно ГОСТ 11262-2017. Перед определением деформационно-прочностных характеристик проводили кондиционирование образцов по ГОСТ 12423-66 в течение 6 ч при температуре $(23 \pm 1)^{\circ} \mathrm{C}$. Количество образцов в каждом испытании 5 шт. Плотность образцов определяли на приборе Balance SX 105 Mettler Toledo (ГОСТ 15139-69).

Расчет энергии активации термоокислительной деструкции композиций проводили согласно методике [15] по кривым ТГ, снятым на приборе TGA/DSCI, Neitzsch STA 449 F3 (Германия). Измерения проводили при следующих условиях: разрешение - 1 мкг, конечная температура $-500^{\circ} \mathrm{C}$, скорость подъема температуры составляла $10^{\circ} \mathrm{C} /$ мин, точность контроля температуры $\pm 2^{\circ} \mathrm{C}$.

Определение плотности исследуемых композиций до и после старения показало, что использование всех исследуемых добавок приводит к незначительному увеличению плотности, что можно объяснить как низким процентом ввода добавок от 1 до 2 мас. \%, так и тем, что плотность добавок несколько выше плотности чистого полимера. Исключение составляет композиция ПЭНД с осушителем, для которого введение незначительного количества добавки (1 мас. \%) приводит к увеличению плотности на $6,3 \%$, что связано с высокой плотностью самого наполнителя. Введение в полиэтиленовую матрицу ADDITIVE 13169 в концентрации 10 мас. \% приводит к повышению плотности на 4,44\%. При использовании EFPP 1001 E-Filler в концентрации 10 мас. \% наблюдается увеличение плотности на 5,6\%. Это объясняется тем, что плотность мела и талька значительно превышает плотность самого полимера (порядка

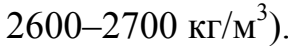

В результате теплового старения наблюдается некоторое снижение плотности нестабилизированных композиций ПЭНД. Плотность снижается на $1,8-6,9 \%$ в зависимости от состава композиций. Для чистого ПЭНД плотность снижается с 942 до 928 кг $/ \mathrm{m}^{3}$. Это можно объяснить тем, что при повышенных температурах в присутствии кислорода воздуха в полимере протекают процессы деструкции, которые приводят к уменьшению длины макромолекул полимера, потере массы образца и снижению плотности. Образуется более дефектная, разрыхленная структура полимера, которая имеет 
меньшую плотность. Для композиций ПЭНД, содержащих кроме функциональных добавок также стабилизатор Hostanox 0,3\%, происходит аналогичное постепенное понижение плотности, однако снижение плотности происходит менее интенсивно. Результаты определения твердости для исследуемых композиций на основе ПЭНД представлены в табл. 1.

Из таблицы видно, что при введении функциональных добавок в ПЭНД происходит снижение твердости с 61,7 до 56,3 в зависимости от типа добавки. Особенно значительное понижение наблюдается при введении скользящей добавки DL 5644, антистатиков AE 50025 и ПОАЭ, антиблока ПОАБ 12. Это связано с принципом действия добавок. Так, скользящие добавки изменяют свойства поверхности полимерных материалов, уменьшая поверхностное трение. Они обладают низкой совместимостью с полимером, происходит миграция на поверхность веществ меньшей молекулярной массы, в результате чего поверхностная твердость полимера уменьшается. В результате теплового старения происходит повышение значений твердости по Шору Д для всех исследуемых композиций - как нестабилизированных, так и стабилизированных. Это объясняется тем, что при старении полимеров могут происходить процессы частичного структурирования, наблюдается сближение макромолекул и усиление межцепных взаимодействий. В результате происходит образование поперечных связей, что приводит к повышению прочности и твердости материалов. Особенно заметно увеличение твердости на 7,6\% после старения для стабилизированной композиции с антипиреном FR 400, что также согласуется с данными, полученными при определении плотности образцов.

Результаты определения относительного удлинения при разрыве исследуемых композиций ПЭНД до и после старения в течение 300 ч представлены в табл. 2. Полученные данные свидетельствуют о том, что введение функцио- нальных добавок даже в относительно небольшом количестве (1-2 мас. \%) приводит к значительному изменению относительного удлинения при разрыве ПЭНД. Относительное удлинение значительно снижается в зависимости от состава композиций. Максимальное снижение $\varepsilon$ на 27,1 и $36,8 \%$ происходит для композиций, содержащих 10 мас. \% талька и 1 мас. \% осушителя. Интересен факт, что именно введение небольшого количества осушителя приводит к наибольшему изменению удлинения, что возможно связано с крупным размером частиц, которые выступают в качестве центров концентрации напряжений в полимерной матрице. Использование скользящей добавки ADDITIVE DL 5644 и пигмента White 41110 не приводит к значительному изменению относительного удлинения ПЭНД, а при введении антистатика ПОАЭ 23 его значения несколько увеличиваются. Известно, что в качестве антистатиков производители используют органические материалы относительно низкой молекулярной массы, такие как сложные эфиры жирных кислот, алкиламины и др., способные мигрировать на поверхность полимера, выполняя роль пластификаторов [12]. Скользящие добавки, используемые в переработке пластмасс, чаще всего представляют собой амиды жирных кислот, выступающие в виде внутренних смазок, увеличивающие подвижность крупных элементов надмолекулярной структуры полимера и способствующие лучшей деформируемости. К неорганическим соединениям относится пигмент White 41110, представляющий собой диоксид титана, который обладает высокой атмосферо- и светостойкостью, а также отличной укрывистостью, что позволяет обеспечить хороший цвет при небольшой концентрации пигмента. На изменение деформационно-прочностных свойств композиции большое влияние оказывает процентное содержание наполнителя. В работе используются антистатики в концентрации 2 мас. \%, которая не вызывает резкого изменения свойств.

Таблица 1

Изменение твердости композиций на основе ПЭНД в результате теплового старения

\begin{tabular}{|l|c|c|c|c|}
\hline \multirow{2}{*}{ Композиция } & \multicolumn{4}{|c|}{ Твердость по Шору D } \\
\cline { 2 - 5 } & Без стабилизатора & \multicolumn{2}{c|}{ Со стабилизатором } \\
\cline { 2 - 5 } & 0 ч & 300 ч & 0 ч & 300 ч \\
\hline ПЭНД & 61,7 & 61,8 & 60,8 & 61,4 \\
\hline ПЭНД + мел ЕFPР 1001 (10\%) & 60,6 & 63,8 & 60,5 & 62,6 \\
\hline ПЭНД + тальк ADDITIVE 13169 (10\%) & 59,3 & 61,4 & 61,4 & 60,8 \\
\hline ПЭНД + скользящая добавка ADDITIVE 5540 (2\%) & 59,9 & 64,7 & 60,8 & 63,6 \\
\hline ПЭНД + антистатик АЕ 50025 (2\%) & 58,5 & 61,7 & 60,3 & 62,9 \\
\hline ПЭНД + скользящая добавка ADDITIVE DL 5644 (2\%) & 59,5 & 63,2 & 60,5 & 64,9 \\
\hline ПЭНД + антиблок РЕ-АВ 50035 (2\%) & 59,3 & 61,1 & 60,4 & 64,3 \\
\hline ПЭНД + пигмент «Реалпакс 10030» (1\%) & 60,1 & 62,2 & 60,7 & 63,4 \\
\hline
\end{tabular}


Окончание табл. 1

\begin{tabular}{|l|c|c|c|c|}
\hline \multirow{2}{*}{\multicolumn{2}{|c|}{ Композиция }} & \multicolumn{4}{|c|}{ Твердость по Шору D } \\
\cline { 2 - 5 } & Без стабилизатора & \multicolumn{2}{c|}{ Со стабилизатором } \\
\cline { 2 - 5 } & 0 ч & 300 ч & 0 ч & 300 ч \\
\hline ПЭНД + осушитель POLI-CH DC 451 (1\%) & 59,8 & 65,2 & 60,7 & 62,3 \\
\hline ПЭНД + антипирен FR 400 (12\%) & 59,9 & 64,2 & 60,7 & 65,4 \\
\hline ПЭНД + пигмент White 41110 (1\%) & 57,5 & 64,6 & 60,5 & 64,5 \\
\hline ПЭНД + антиблок ПОАБ 12 (2\%) & 56,3 & 61,1 & 59,7 & 61,7 \\
\hline ПЭНД + антистатик ПОАЭ 23 (2\%) & 58,5 & 61,7 & 60,3 & 64,5 \\
\hline
\end{tabular}

Таблица 2

Значения относительного удлинения при разрыве в зависимости от состава композиции

\begin{tabular}{|l|c|c|c|c|}
\hline \multirow{2}{*}{\multicolumn{2}{|c|}{ Композиция }} & \multicolumn{3}{|c|}{ Относительное удлинение при разрыве, \% } \\
\cline { 2 - 5 } & \multicolumn{2}{|c|}{ Без стабилизатора } & \multicolumn{2}{c|}{ Со стабилизатором } \\
\cline { 2 - 5 } & 0 ч & 300 ч & 0 ч & 300 ч \\
\hline ПЭНД & 118 & 82 & 110 & 89 \\
\hline ПЭНД + мел ЕFPР 1001 (10\%) & 104 & 80 & 103 & 70 \\
\hline ПЭНД + тальк ADDITIVE 13169 (10\%) & 82 & 31 & 75 & 24 \\
\hline ПЭНД + скользящая добавка ADDITIVE 5540 (2\%) & 94 & 89 & 95 & 66 \\
\hline ПЭНД + антистатик AЕ 50025 (2\%) & 97 & 70 & 87 & 78 \\
\hline ПЭНД + скользящая добавка ADDITIVE DL 5644 (2\%) & 111 & 92 & 92 & 93 \\
\hline ПЭНД + антиблок РЕ-AВ 50035 (2\%) & 94 & 86 & 85 & 60 \\
\hline ПЭНД + пигмент «Реалпакс 10030» (1\%) & 105 & 79 & 71 & 59 \\
\hline ПЭНД + осушитель РОLI-CH DC 451 (1\%) & 72 & 42 & 64 & 23 \\
\hline ПЭНД + антипирен FR 400 (12\%) & 89 & 86 & 87 & 65 \\
\hline ПЭНД + пигмент White 41110 (1\%) & 112 & 102 & 108 & 79 \\
\hline ПЭНД + антиблок ПОАБ 12 (2\%) & 101 & 98 & 104 & 88 \\
\hline ПЭНД + антистатик ПОАЭ 23 (2\%) & 116 & 86 & 117 & 77 \\
\hline
\end{tabular}

Из таблицы видно, что в ПЭНД под действием повышенной температуры интенсивно протекают процессы деструкции. Так, после 300 ч старения относительное удлинение для чистого ПЭНД снижается на $10,1 \%$, что свидетельствует о развитии деструктивных процессов в полимере. Воздействие повышенной температуры также приводит к снижению относительного удлинения при разрыве и для композиций, содержащих функциональные добавки. Причем при использовании таких добавок, как тальк и осушитель падение относительного удлинения максимально. Композиции со скользящими добавками ADDITIVE 5540 и ADDITIVE DL 5644, пигментом White 41110, антиблоком ПОАБ 12 показывают наиболее высокие значения относительного удлинения при разрыве после старения. Таким образом, можно сделать вывод о неоднозначности влияния функциональных добавок на изменение свойств ПЭНД в результате старения. В некоторых случаях введение добавок замедляет развитие деструктивных процессов в полимере, а в других, наоборот, усиливает их. Необходимо учитывать химическую природу добавок, наличие функциональных групп, возможность ми- грации и другие аспекты. В случае применения для ПЭНД Hostanox в концентрации 0,3 мас. \% наблюдается стабилизирующий эффект. Так, после старения в течение 300 ч значение удлинения для стабилизированной композиции на $11,7 \%$ выше, чем для композиции без стабилизатора. Для композиций с антистатиком AE 50025, скользящими добавками ADDITIVE DL 5644 и Hostanox наблюдается стабилизирующий эффект. Выявлен эффект антагонизма при совместном использовании в ПЭНД стабилизирующей добавки Hostanox 03 и пигмента White 41110. Так, после старения в течение 300 ч относительное удлинение для композиции ПЭНД + White 41110 составило $102 \%$, в то время как при введении в композицию дополнительно стабилизатора Hostanox 03 значения удлинения падают до 79\%, что свидетельствует о возможном взаимодействии добавок, приводящем к снижению эффективности стабилизатора. Аналогичный эффект наблюдается при использовании таких добавок, как осушитель, антиблок РЕ-АВ 50035 и антистатик ПОАЭ 23. Таким образом, при совместном использовании стабилизирующей добавки Hostanox 03 и большинства функциональных добавок наблюдаются антагонистические 
эффекты, когда происходит дезактивация стабилизатора. Это может происходить при взаимодействии стабилизатора и наполнителей, в результате чего стабилизатор выводится из зоны реакции и не выполняет свою функцию. Возможно также взаимодействие функциональных групп стабилизатора с функциональными группами низкомолекулярных добавок, приводящее к потере ингибирующей способности стабилизатора.

На рисунке приведены кривые изменения массы образца при повышении температуры до $300^{\circ} \mathrm{C}$ для чистого ПЭНД (а) и ПЭНД со стабилизатором Hostanox 03 (б), полученные совмещенным методом ТГ/ДСК. На основании полученных температурных кривых были определены температура плавления для чистого ПЭНД $137,6^{\circ} \mathrm{C}$ и температура начала деструкции $-254^{\circ} \mathrm{C}$.

Введение стабилизатора в ПЭНД приводит к некоторому повышению температуры плавления до $140,9^{\circ} \mathrm{C}$, а температура максимальной скорости окисления повышается до $268,2^{\circ} \mathrm{C}$. Из рисунка видно, что при введении стабилизатора происходит увеличение степени кристалличности полимера, о чем свидетельствует увеличение площади пика плавления с 136,5 до 170,7 Дж/г. Возможно, введение стабилизирующей добавки увеличивает долю кристаллической фазы в полимере или размер кристаллитов, что приводит и к росту температуры плавления. Температура максимальной скорости окисления стабилизированной композиции увеличивается до $268,2^{\circ} \mathrm{C}$, а площадь окисления, т. е. количество теплоты, выделяемое при окислении полимера, снижается с 91,04 Дж/г

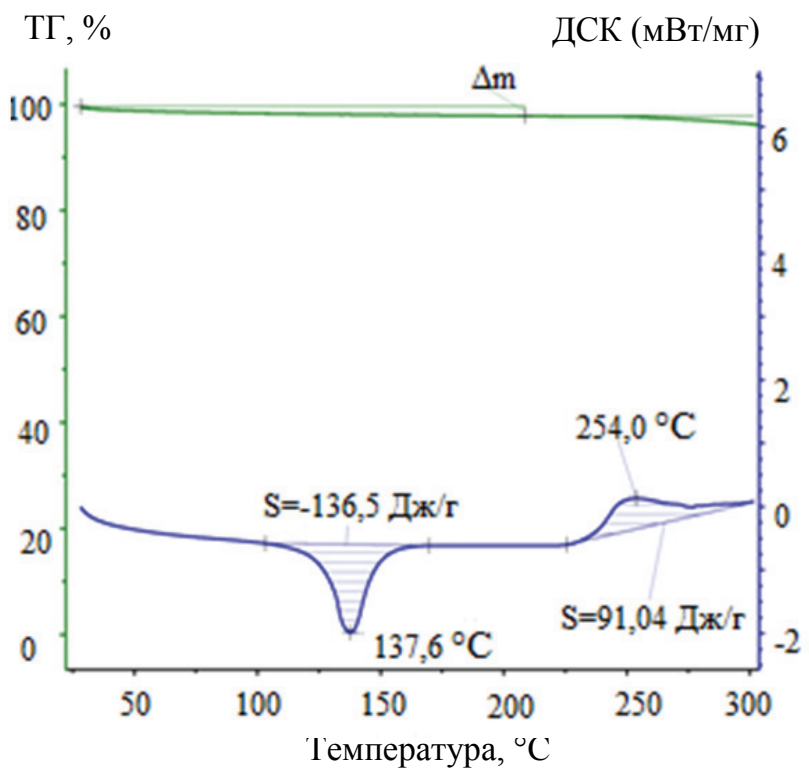

$a$ (для чистого ПЭНД) до 85,4 Дж/г, что свидетельствует о замедлении процесса окисления и эффективности действия стабилизатора.

Также по полученным кривым были рассчитаны значения энергии активации термоокислительной деструкции. Для чистого ПЭНД энергия активации термоокислительной деструкции составила 76 кДж/моль, для стабилизированного ПЭНД 91 кДж/моль, что свидетельствует об эффективности действия стабилизатора. Значения энергии активации термоокислительной деструкции были получены и для других композиций. Так, для композиции ПЭНД + ЕFРР 1001 значение энергии активации составляет 70 кДж/моль, дополнительное введение в композицию стабилизирующей добавки приводит к снижению энергии активации до 45 кДж/моль, что подтверждает значения деформационных свойств и эффект антагонизма.

Заключение. Проведенные исследования композиций на основе ПЭНД свидетельствуют о неоднозначности в изменении устойчивости композиций к тепловому старению при совместном использовании нескольких функциональных добавок. В ходе работы выявлены случаи как синергизма, так и антагонизма в изменении свойств при совместном использовании функциональных добавок и стабилизаторов. Данный факт должен быть учтен при составлении рецептур полимерных композиций с целью получения материалов с наилучшим комплексом свойств, а также предупреждения возможного перерасхода дорогостоящих добавок.

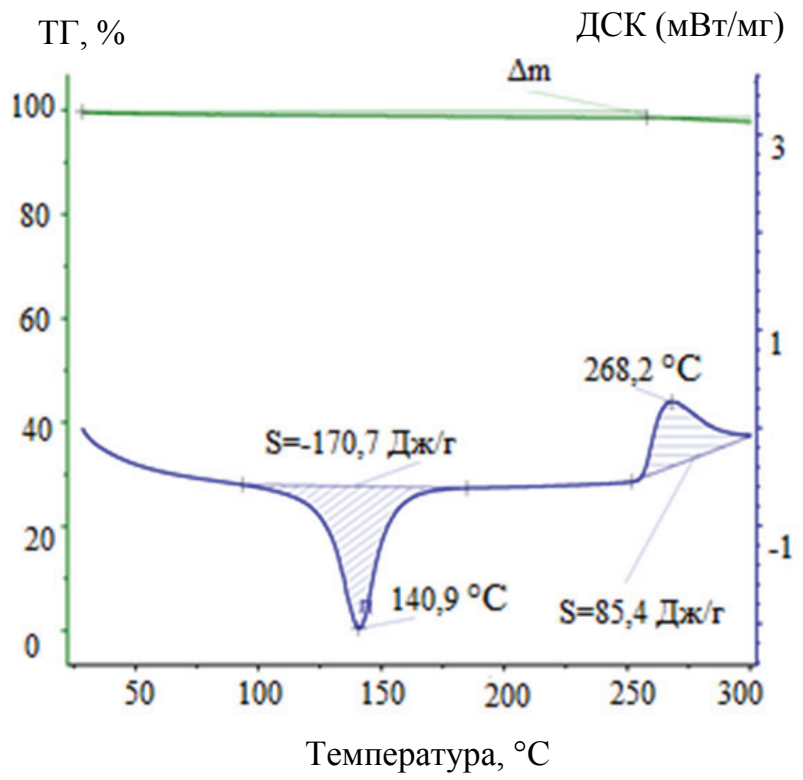

$\sigma$

Кривые ТГ/ДСК для чистого ПЭНД (а) и ПЭНД со стабилизатором (б) 


\section{Список литературы}

1. Шаов А. Х., Кодзокова Э. Х. Органические производные пятивалентного фосфора в качестве стабилизаторов и модификаторов полимерных материалов // Пластические массы. 2005. № 3. С. 33-39.

2. Пфенднер Р. Добавки сегодня и в будущем // Полимерные материалы. 2007. № 9. С. 2-7.

3. Wilen C.-E., Pfaender R. Improving Weathering Resistance of Flame-Retarded Polymers // Journal of Applied Polymer Science. 2013. Vol. 129, № 6. P. 925-944. DOI:10.1002/app.38979.

4. Interactions between carbon black and stabilizers in LDPE thermal oxidation / J. M. Pena [et al.] // Polymer Degradation and Stability. 2001. Vol. 72, № 1. P. 163-174.

5. Gerard C., Fontaine G., Bourbigo S. Synergistic and antagonistic effects in flame retardancy of an intumescent epoxy resin // Polymers Advanced Technologies. 2011. Vol. 22, № 7. P. 1085-1090. DOI: 10.1002/pat.1996.

6. Машко Т. Л., Калугина Е. В. Влияние новых медьсодержащих добавок на термоокислительную стабильность поликапроамида // Пластические массы. 2006. № 1. С. 37-41.

7. Гордиенко В. П., Сальников В. Г. Структура и физико-механические свойства линейного полиэтилена, содержащего смесь ZnO-ZnS, при УФ-облучении // Пластические массы. 2007. № 6. С. 6-9.

8. Екимов А. И., Айзинсон И. Л., Кулачинская О. Б. Некоторые аспекты антагонизма компонентов в термопластичных полимерных материалах // Полимерные материалы. 2007. № 9. С. 6-11.

9. Thermal degradation of polyethylene containing antioxidant and hydrophilic/hydrophobic silica / Yu. Bolbukh [et al.] // Journal of Thermal Analysis and Calorimetry. 2008. Vol. 94, № 3. P. 727-736.

10. Изделия полимерные для строительства. Метод определения долговечности по энергии активации термоокислительной деструкции полимерных материалов: СТБ 1333.0-2002. Минск: Минстройархитектуры, 2002. 11 с.

11. Взаимное влияние наполнителей и стабилизаторов в полимерных композиционных материалах / Л. А. Ленартович [и др.] // Труды БГТУ. 2011. № 4 (142): Химия, технология орган. в-в и биотехнология. С. 98-102.

12. Lenartovich L. A., Prokopchuk N. R. Method off the Increase of Thermostability of Filled Polymer // Innovations in Chemical Physics and Mesoscopy: Applied Mathematical Models and Experimental Approaches in Chemical Science. 2016. Vol. 3. P. 151-155.

13. Effect of titanium dioxide on the properties of polyethylene/ $\mathrm{TiO}_{2}$ nanocomposites. Composites Part B / V. G. Nguyen [et al.] // Engineering. 2013. № 45 (1). P. 1192-1198. DOI: 10.1016/ j.compositesb.2012.09.058.

14. Синергизм в процессах модификации полиолефинов / С. С. Галибеев [и др.] // Химия и химическая технология. 2004. Т. 47, № 3. С. 168-172.

15. Цвайфель Х., Маер Р. Д., Шиллер М. Добавки к полимерам. Справочник. СПб.: Профессия, 2010. 1144 c.

\section{References}

1. Shaov A. Kh., Kodzokova E. Kh. Organic derivatives of pentavalent phosphorus as stabilizers and modifiers of polymer materials. Plasticheskiye massy [Plastic masses], 2005, no. 3, pp. 33-39 (In Russian).

2. Pfendner R. Additives today and in the future. Polimernyye materialy [Polymer materials], 2007, no. 9, pp. 2-7 (In Russian).

3. Wilen C.-E., Pfaender R. Improving Weathering Resistance of Flame-Retarded Polymers. Journal of Applied Polymer Science, 2013, vol. 129, no. 6, pp. 925-944. DOI: 10.1002/app.38979.

4. Pena J. M., Allen N., Edge M., Liauw B., Valange B. Interactions between carbon black and stabilisers in LDPE thermal oxidation. Polymer Degradation and Stability, 2001, vol. 72, no. 1, pp. 163-174.

5. Gerard C., Fontaine G., Bourbigo S. Synergistic and antagonistic effects in flame retardancy of an intumescent epoxy resin. Polymers Advanced Technologies, 2011, vol. 22, no. 7, pp. 1085-1090. DOI: 10.1002/pat.1996.

6. Mashko T. L., Kalugina E. V. Influence of new copper-containing additives on the thermal-oxidative stability of polycaproamide. Plasticheskiye massy [Plastic masses], 2006, no. 1, pp. 37-41 (In Russian).

7. Gordienko V. P., Salnikov V. G. Structure and physico-mechanical properties of linear polyethylene containing a mixture of zinc oxide on the central nervous system, at UV-irradiation. Plasticheskiye massy [Plastic masses], 2007, no. 6, pp. 6-9 (In Russian).

8. Ekimov A. I., Ayizinson I. L., Kulachinskaya O. B. Some aspects of antagonism of components in thermoplastic polymer materials. Polimernyye materialy [Polymer materials], 2007, no. 9. pp. 6-11 (In Russian). 
9. Bolbukh Yu., Kuzema P., Tertykh V., Laguta I. Thermal degradation of polyethylene containing antioxidant and hydrophilic/hydrophobic silica. Journal of Thermal Analysis and Calorimetry, 2008, vol. 94, no. 3 , pp. $727-736$.

10. STB 1333.0-2002. Polymer products for construction. Method for determining the durability of the activation energy of thermooxidative destruction of polymer materials. Minsk, Minstroyarchitektury Publ., 2002. 11 p. (In Russian).

11. Lenartovich L. A., Prokopchuk N. R., Yatsenko V. V., But'ko T. A. Mutual influence of fillers and stabilizers in polymer composite materials. Trudy BGTU [Proceedings of BSTU], 2011, no. 4 (142): Chemistry, Organic Substances Technology and Biotechnology, pp. 98-102 (In Russian).

12. Lenartovich L. A., Prokopchuk N. R. Method off the Increase of Thermostability of Filled Polymer. Innovations in Chemical Physics and Mesoscopy: Applied Mathematical Models and Experimental Approaches in Chemical Science, 2016, vol. 3, pp. 151-155.

13. Nguyen V. G., Thai H., Mai D. H., Tran H. T., Tran D. L., Vu M. T. Effect of titanium dioxide on the properties of polyethylene/ $\mathrm{TiO}_{2}$ nanocomposites. Composites Part B. Engineering, 2013, no. 45 (1), pp. 1192-1198. DOI: 10.1016/j.compositesb.2012.09.058.

14. Galibeyev S. S., Kochnev A. M., Arkhireyev V. P., Spiridonova R. R. Synergism in the processes of polyolefin modification. Khimiya i khimicheskaya tekhnologiya [Chemistry and Chemical Technology], 2004, vol. 47, no. 3, pp. 168-172 (In Russian).

15. Zweifel H., Maer R. D., Shiller M. Dobavki k polimeram. Spravochnik [Additives to polymers. Reference book]. St. Petersburg, Professiya Publ., 2010. 1144 p.

\section{Информация об авторах}

Ленартович Лилия Алексеевна - кандидат технических наук, старший преподаватель кафедры полимерных композиционных материалов. Белорусский государственный технологический университет (220006, г. Минск, ул. Свердлова, 13а, Республика Беларусь). E-mail: lenartovich@belstu.by

Прокопчук Николай Романович - доктор химических наук, профессор, член-корреспондент Национальной академии наук Беларуси, профессор кафедры полимерных композиционных материалов. Белорусский государственный технологический университет (220006, г. Минск, ул. Свердлова, 13a, Республика Беларусь). E-mail: nrprok@gmail.com

Касперович Ольга Михайловна - кандидат технических наук, доцент, доцент кафедры полимерных композиционных материалов. Белорусский государственный технологический университет (220006, г. Минск, ул. Свердлова, 13a, Республика Беларусь). E-mail: kasperovichvolha@yandex.by

\section{Information about the authors}

Lenartovich Liliya Alekseevna - PhD (Engineering), Senior Lecturer, the Department of Polymer Composite Materials. Belarusian State Technological University (13a, Sverdlova str., 220006, Minsk, Republic of Belarus). E-mail: lenartovich@belstu.by

Prokopchuk Nikolay Romanovich - DSc (Chemistry), Professor, Corresponding Member of the National Academy of Sciences of Belarus, Professor, the Department of Polymer Composite Materials. Belarusian State Technological University (13a, Sverdlova str., 220006, Minsk, Republic of Belarus). E-mail: nrprok@gmail.com

Kasperovich O'Iga Michailovna - PhD (Engineering), Associate Professor, Assistant Professor, the Department of Polymer Composite Materials. Belarusian State Technological University (13a, Sverdlova str., 220006, Minsk, Republic of Belarus). E-mail: kasperovichvolha@yandex.by 